\title{
History Repeating ... Disaster-Related Intercountry Adoption and the Psychosocial Care of Children
}

\author{
Patricia Fronek* and Denise Cuthbert** \\ *School of Human Services and Social Work, Griffith University \\ E-mail: p.fronek@griffith.edu.au \\ **School of Graduate Research, RMIT University \\ E-mail: denise.cuthbert@rmit.edu.au
}

Disasters are prevalent with devastating effects on vulnerable populations that include the elderly, disabled, women and children. Historical responses to vulnerable children and families post-disaster raise questions concerning further harms to children rescued by adoption in the aftermath of devastation. This article offers critical and historical perspectives on child removal for adoption in the context of disaster and the psychosocial care of children affected by disaster. It brings into question whether removal, especially permanent removal for adoption, is in their interests. This article concludes that efforts are needed by the international community to ensure that past abuses do not recur.

Key words: intercountry adoption, post-disaster, children, international community, psychosocial care of children.

\section{Introduction}

Intercountry adoption (ICA) is entwined with the annals of modern geo-political and environmental disaster. World War II, the Korean and Vietnam wars, the fall of Ceausescu's regime in Romania, the collapse of the Soviet bloc, famine and civil war in Africa, earthquakes, and tsunamis mark significant moments in the development of intercountry adoption from the mid-twentieth century to the present, as evinced most recently by events in Haiti in 2010. While ICA originated as a humanitarian response to children in disasters, in the last decades of the twentieth century it became an accepted route to family formation in many western countries (Cuthbert et al., 2009; Fronek, 2009)) to the point that ICA is now demand - as distinct from needs - driven. Further, developments in knowledge on the psychosocial care of children and communities in crisis raise questions about the appropriateness of the permanent removal of children during and immediately after disasters (Lesnick and Urek, 2010; Sommers-Flanagan, 2007). This literature has not previously been examined in relation to ICA.

This article offers critical and historical perspectives on child removal for adoption in the context of disaster and how considerations of best practice in psychosocial care post-disaster bear on the question of whether removal, especially permanent removal for adoption, is in the interests of children. We outline the connections between disaster and ICA and note the persistence of rescue rhetoric deployed to support the removal of children from disaster zones for adoption. An exploration of literature on the psychosocial care and management of children in post-disaster contexts follows. We conclude that expatriating 
children evacuated for adoption post-disaster has been repeated too often in the modern period. Greater efforts are needed by the international community to ensure that market forces driving the removal and adoption of children are not permitted to prevail over considerations of the best interests of children and their communities.

\section{Not all disasters are equal}

Disasters are prevalent (Cameron et al., 2009; Leivesley, 1980; Margesson and TaftMorales, 2010; Nicolas et al., 2009; UN/ISDR, 2007) and have differential impact within and across nations. In affluent, developed nations, infrastructure that supports disaster preparedness and recovery may ameliorate the impact of disaster. Poorer nations exposed to the full brunt of disaster may struggle to absorb foreign aid and humanitarian assistance in disaster recovery. The impact of disaster on populations within nations also varies: with the poor, disenfranchised, disabled, women, the very young and older people being most vulnerable during and after disaster (Alam, 2010; Enarson and Phillips, 2008). Reflecting the flow of children in adoption generally, in which the children of poor parents are transferred to more affluent families, only certain disasters see children removed for adoption. Historically, children most vulnerable to this intervention are those in poor countries where established ICA networks can quickly facilitate new adoptions and expedite those in process (Dambach and Baglietto, 2010; Fronek and Cuthbert, 2012). Under such circumstances, it is questionable whether the adoption of children is so much a humanitarian response to disaster as an opportunity for expedited and increased flows of children. The dynamics of global power, economics and race at work in ICA come starkly into view when consideration is given to the circumstances in which one disaster - such as the Haitian earthquake in 2010 - might serve as an opportunity for the mass removal of children for adoption, while in other disasters - such as the extended earthquake crisis on New Zealand's South Island continuing since late 2010 - the post-disaster care of children proceeds without any question of permanent removal from their devastated and displaced families and communities.

Children in war-torn Vietnam, post-Ceausescu Romania, and post-earthquake Haiti were subject to mass removal by foreigners for adoption. It is unthinkable that foreign groups or individuals might 'rescue' children impacted by disasters in the west by removing them and placing them with adoptive families overseas. It is unimaginable that US children affected by Hurricane Katrina in 2005, or Australian children displaced by the catastrophic bushfires in the Australian state of Victoria in 2009 or by the floods which inundated the states of Queensland, New South Wales and Victoria in 2010-11 might be airlifted from their communities for adoption by foreigners. Why, therefore, does the permanent removal of children from disasters in poor nations appear acceptable? In more developed nations, different considerations pertain. For example, a priority for children separated from their legal guardians immediately post-Katrina was reunification (despite criticism of post-Katrina management). In the 2011 Australian floods, where the scale of the recovery was likened to the aftermath of war, the immediate post-disaster focus was on building community resilience (ABC, 2011; Brandenburg et al., 2007). Both implicitly and explicitly, keeping children in these communities is considered central to the task of re-building. Yet, in poor countries, adoption remains coupled with humanitarianism (ISS, 2010: 9) and presents as a valid - even worthy - response to children in disaster. 


\section{The persistence of child rescue narratives}

Interventions by adoption agencies and individuals remain problematic in post-disaster ICA. In these situations, there is little evidence of critically reflective practice that might better inform future approaches to ICA (Bergquist, 2009; Brookfield, 2009; Fronek, 2012). In disasters, there is frequently a failure of governments and legal systems including international legal frameworks to respond appropriately. Consequently, inadequate attention is paid to crucial child welfare issues in the face of attempts to remove children from disaster zones for adoption. In several well-publicised incidents, people engaged in child trafficking in disaster zones have been pardoned and released (Rotabi and Bergquist, 2010). Further, the language used to describe serious breaches of law with respect to child removal for adoption minimises the illegality, referring to 'scandals' or 'scams' rather than crimes. Each disaster, man-made or otherwise, creates circumstances perceived as exceptional and thereby justifying extraordinary action by those who promote adoption. The notion of 'exception' creates the slippery slope that allows the dismantling of safeguards, legitimises the expedition of adoption processes and bends rules despite advice from international organisations to the contrary (Doyle, 2010; UNICEF, 2009; UNICEF, 2010; ISS, 2010). In contrast with disaster in more developed countries, heightened disaster and rescue discourses work to create a homogenously apocalyptic view of the disaster zone as a place where no care for children appears possible: effectively all or many children are viewed as 'orphans' in need of rescue (and available for adoption). The people, culture and nation caught up in disaster are represented as wholly dysfunctional: and the child in disaster is seen as isolated, disconnected from family, caregivers, peers and community.

The Machel Report (UN, 1996) outlines harms for children separated from caregivers and evacuated during crises, including exploitation on the adoption market. In the event of imminent danger, the report recommends families be evacuated rather than separating children from caregivers. UNICEF, UNHCR, the UN Committee on the Rights of the Child, the Hague Conference on Private International Law, the International Committee of the Red Cross and international NGOs such as the Save the Children Alliance and International Social Service share views on ICA post-disaster as outlined by UNICEF:

The case of children separated from their families and communities during war or natural disasters merits special mention. Family tracing should be the first priority and intercountry adoption should only be envisaged for a child once these tracing efforts have proved fruitless, and stable in-country solutions are not available. (UNICEF, 2010)

The position of UNICEF and other organisations on ICA are denigrated as 'antiadoption' by those with vested interests in the promotion of less regulated ICA (Fronek, 2009; Bartholet, 2010; Fronek and Tilse, 2010; Poe, 2010). ICA in disaster situations seems to operate in a privileged space beyond law and standard adoption practices: its assumed inherent good remains unquestioned by proponents. History shows that disasters open doors for criminal and unethical activities. As with prevention strategies that aim to address causal issues that separate families in the first instance (Fronek and Cuthbert, 2012), the child welfare literature that emphasises care in the context of families and communities bears little relationship to post-disaster adoption practice. 
Pro-adoption discourse assumes that harms experienced by children adopted postdisaster are less, if they exist at all, than those to which children may be exposed through staying in a disaster zone (Kelley, 2010). In rescue discourse, no alternatives to child removal for adoption are offered. Whether children are assumed or verified orphans, placements in western, nuclear, families, usually Christian, are considered superior options for their care (Doyle, 2010). This assumption persists despite concerns expressed by academics and international agencies about child removal compounding the effects of loss and harm caused by separation from families/carers, communities and culture, diminished chances of reunification and the severing of legal ties (Kelley, 2010). The growing body of knowledge concerning psychosocial care post disaster bears directly on the removal of children for adoption from disaster zones. Notably, this literature has not been explored in relation to adoption. Before turning to this literature, the intertwined histories of ICA and disaster are outlined.

\section{A brief history of ICA post-disaster}

The origin of ICA as an international practice is tied to disaster. Key moments in the history of ICA are a series of geo-political and environmental disasters which provided occasions for children to be permanently removed by foreign nationals, as discussed below.

\section{The Korean War (1950-1953)}

Although modern ICA began during World War II, the Korean War is important as the concept of 'rescuing children by adoption' took hold on a large scale in its aftermath (Fronek, 2009). The rise of ICA as a humanitarian act, the establishment of adoption agencies and the sanction by churches, governments, law makers and politicians in the west prepared the way for future evacuations and adoptions of children from emergency situations (Fronek, 2009). In a country devastated by war and poverty, many children were placed in orphanages founded by US organisations that worked towards their international adoption. The rise of Korean ICA in the decades following World War II was escalated by powerful interests in receiving countries, including increasingly vocal and well-organised groups of adoptive parents, cold war politics and 'rescue' discourses attractive to both the religious right and liberal left. The rise of ICA as a 'solution' to child poverty and suffering effectively stunted the development of other welfare solutions (Sarri et al., 1998). Korean ICA emerged as a world leader with over 160,000 children adopted internationally since the 1950s (Selman, 2009). In Korea, an extended post-disaster period of almost sixty years created a precedent for ICA, legitimising organised child rescue by adoption from disaster zones in developing nations.

\section{Vietnam: Operation Babylift (1975)}

Christian adoption agencies, including Holt, Friends for the Children of Vietnam (FCV) and Pearl S. Buck Foundation, with roots in South Korea, spread and were well established in Southeast Asia by the 1970s (Edwards, 1997). It was the influence of their network on western governments that enabled the mass evacuation of children for ICA in events known as Operation Babylift in April 1975. Operation Babylift has historically been 
represented as a humanitarian action necessary to save the lives of these children. What is rarely acknowledged is that the evacuation was initiated by those keen to see the finalisation of adoptive placements already underway and threatened by the fall of Saigon and the imminent Communist victory in Vietnam (Fronek, 2012). Inevitably in the chaos of the end of the war, many children who left Vietnam and were later adopted in North America, Europe and Australia were neither orphans nor available for adoption (Zigler, 1975, 1976; Brown, 1980; Bergquist, 2009).

Operation Babylift has been criticised by many including Vietnamese communities and more recently Vietnamese adoptees (Bergquist, 2009; Brookfield, 2009; Cherot, 2009). Harms to children resulted from actions fuelled by Cold War politics and adoptiondriven organisations presenting as welfare bodies. There were no attempts at family reunification and even when families managed to locate their children, most never regained custody. Children had legal ties severed, personal histories and culture lost, and for many there was little to no hope of tracing family or community. Despite many positive experiences in adoptive families, adoptees report negative consequences of 'being rescued', expectations of gratitude to their 'rescuers' and racism (Armstrong and Slaytor, 2001; Cherot, 2009).

The Boxing Day Tsunami (2004)

Indonesia offers a salient counterpoint to other post-disaster experiences where adoption promoters were successful in securing the evacuation of children for adoption. In December 2004, an earthquake triggered tidal waves affecting millions of people in eleven countries bordering the Indian Ocean (Rofi et al., 2006). In Aceh alone, 128,645 people died, 37,063 were missing and 532,898 were displaced. The majority killed were children, women and older people. Despite international pressure to adopt 'orphaned' children, Indonesia, an Islamic country with strict laws relating to ICA, proactively prevented the removal of children after the tsunami. Efforts, instead, focused on recovery, reunification and the prevention of child trafficking (Lauten and Lietz, 2008). UNICEF and the International Justice Commission acted swiftly in relation to child trafficking concerns in Indonesia, Sri Lanka and Thailand (Kelley, 2010). Highlighting the degree to which prospective adoptive parents see disaster as an adoption opportunity, the Australian government received an influx of inquiries regarding adoption from tsunamizones. Pressure from those in Australia seeking to open adoption programs in these areas prompted an Australian Parliamentary inquiry into ICA in Australia in 2005 that concluded that the rate of adoption in Australia was hampered by 'anti-adoption' attitudes in government agencies (HRSCFHS, 2005).

\section{Central Africa and Zoe's Ark (2007)}

The French organisation, Zoe's Ark, named after a child orphaned in the Boxing Day Tsunami, was formed in its aftermath (BBC News, 2007). Reminiscent of Operation Babylift (Bergquist, 2009), charity workers attempted to airlift over 100 children out of Chad for ICA in 2007. They fraudulently claimed the children were orphans from Darfur where nearly 200 million people were displaced by conflict (Ager et al., 2009) and lied to the children's families (Rotabi and Bergquist, 2010). Despite charges, sentencing and 
serving a six-month prison sentence, the perpetrators of the removal of these children were extradited to France and pardoned.

\section{Earthquake disaster in Haiti (2010)}

A massive earthquake struck Haiti in January 2010 ending a decade of disasters. The death toll reached 200,000 and many people became homeless, displaced and vulnerable (Rotabi and Berquist, 2010). This disaster overlay an impoverished economy and society based on colonisation, slavery and disadvantage (Nicolas et al., 2009). Aggressive child trafficking networks, global demand for adoptive children and inadequate law enforcement were present in Haiti prior to 2010 (Balsari et al., 2010).

The Haitian concept of family stretches beyond the nuclear family to cooperative kinship and neighbourhood relationships that provide a buffer in stressful events and children are often raised by wealthier family members (Payne-Price, 1981; Kelley, 2010). A practice called restovek, an informal system of bonding where a child is promised an education in exchange for work, is also practiced and likened by some to slavery (Hearst, 2010). It is common for parents or other family members to maintain contact with children surrendered temporarily and reclaim them in more prosperous times. Families forced by poverty into placing their children in orphanages return to find them adopted (Balsari et al., 2010). Kelley (2010) reports that the UNICEF estimate of 380,000 pre-existing 'orphans' in Haiti were the result of additional hardship for already disadvantaged families as a result of multiple hurricanes occurring between 2004 and 2007. UNICEF's definition of 'orphan' is for statistical purposes and does not necessarily indicate they are without parents or families (UNICEF, 2009). The Inter-Agency Guiding Principles on Unaccompanied and Separated Children (ICRC, 2004) highlight that many children are placed in orphanages for safety, education, economic and social reasons, rather than orphan status and should have the same civil and political rights as other people.

Despite emphasis by international organisations on the prevention of separation of children from their families and caregivers after disasters (IASC, 2007: 210), US adoption agencies escalated the number of adoptions in Haiti following the earthquake. The response of the US government to pressure exerted by pro-adoption advocates was to lift visa requirements. Adoptions were expedited without adequate screening, incorrect or absent records or children necessarily being at risk (Thompson, 2010). Approximately 1,150 children were evacuated from Haiti for the purposes of adoption (Thompson, 2010). The New York Times reported that even orphanages not affected by the earthquake were emptied. In addition to inadequate processes in Haiti, children were given to US families who had not been assessed or who no longer wanted them (Thompson, 2010).

Ten members of the New Life Children's Refugee Group, a Baptist group from Idaho, were accused of trafficking while attempting to move thirty-three children across the Dominican border for ICA (Rotabi and Bergquist, 2010; Hearst, 2010). All members of the New Life Refugee group have been released and returned to the US despite charges of child abduction and trafficking laid by Haitian authorities. Hearst (2010) reports that Governor Rendell of Pennsylvania expedited the adoptions of fifty-two orphans to the US. Twelve of these children were not orphans. In another incident, a member of All Blessings International, a Christian adoption agency, joined other agencies and flew into Haiti a few days after the earthquake on a private aircraft (Armistead, 2010). Children in an orphanage were evacuated for adoption as soon as clearance was given, while other 
children standing at the airstrip were placed on the flight at the last minute (Armistead, 2010). Children picked up from the airstrip were not legally available for adoption and are now living in an orphanage in the United States, awaiting reunion with their families. Haiti ultimately ceased adoptions not approved prior to the earthquake, with the support of international organisations, to prevent further harms to children from separation and trafficking (Kelley, 2010).

\section{Removal of children during or post-disaster: best practice for children?}

Child trafficking and adoption-driven child rescue are problematic from ethical and legal perspectives, yet more concerning is that actions taken to 'protect' children are driven by personal and/or popular beliefs with little reference to knowledge generated by research. Exploring how contemporary understandings of psychosocial care in disaster management inform the evacuation of children is important when critically reviewing interventions. Where prospective parent groups, adoption agencies and proponent politicians have influence adoptions are expedited. It appears that many seek to use the window of opportunity created by disaster to expedite as many adoptions as possible. A study that examined the long-term psychological impact of evacuation during World War II on children separated from their parents found that adults evacuated as children had more insecure attachment styles and lower levels of present psychological well-being than non-evacuees (Foster et al., 2003). Boyden (1994) discusses research that indicates the experience of conflict has less devastating and less long lasting effects on children than separation from family, social disruption and cultural bereavement. Bland (1997), in a study of adult Italian factory workers evacuated after an earthquake, found distress was greater for evacuees removed far from their social network. This research points to disaster distress as a consequence of social network disruption related to the disaster rather than the disaster itself. A study conducted of a Sri Lankan community following the 2004 tsunami found strong compassion, concern and self-help existed within the community. Distress reported by participants was not focused on the tsunami per se, but rather with their treatment by many of those 'helping' them and the damage created by an aid invasion (Lesnick and Urek, 2010). These studies challenge ready assumptions that evacuation is the most effective action to protect people in disasters. Their findings lead to an exploration of the psychosocial care literature and how research informs post-disaster actions.

\section{Psychosocial aspects of disaster}

Until recently, much of the research in this field has been conducted from a western, biomedical perspective where psychiatry and psychological interventions focus on the deficits and vulnerabilities of individuals. Contemporary understandings of good practice post-disaster has moved from Critical Incident Stress Debriefing (CISD) that seeks to prevent Post Traumatic Stress Disorder (PTSD) in individuals whose assumptions about a safe world have been shattered to a more holistic, contextualised model of psychosocial care that 'views emotional reactions to disaster as normal reactions to an abnormal event' rather than psychopathology (Becker, 2009: 654). Related to this is the emergence of Psychological First Aid (PFA) that assumes strengths and resilience within communities. Western biomedical perspectives may be irrelevant or inappropriate in cultural contexts where beliefs about life events and how to address them may differ (Hobfoll et al., 2007; Tribe, 
2007). Inclusion of cultural differences and knowledge of local communities, particularly in relation to power and resources, are essential in disaster response, although indigenous ways of healing and managing disaster are seldom considered (Crosby and Grodin, 2007; Thirumurthy et al., 2008). Pack-Patton (2010) found that cultural sensitivity is more important than formal training in disaster intervention. Recently, traditional relief responses have shifted to deploying local resources to build local capacity and resilience (Alam, 2010).

The inevitable association of disaster with widespread panic and violence is increasingly challenged by research (Raphael, 2005; Mark, 2008). Evidence from different contexts suggests that survivors rally to help each other and develop adaptive responses that must be recognised, mobilised and strengthened (Raphael, 2005). Caring for children benefits both children and adult survivors and promotes community healing as part of the recovery process (Becker, 2009). In a study of disaster-prone Bangladesh, resilience and coping are identified in ordinary people whose actions rebuild their communities (Alam, 2010). Immediately post-disaster people search for their family members, followed by supporting other members of the community with active participation in recovery across age groups. Instinctive survival strategies that include individual initiatives, kinship ties and obligations and social networking are reported as important to recovery (Alam, 2010).

There have been few systematic studies of children post-disaster, especially in developing countries (Williams et al., 2008). Even less research relates to current adoption practices post-disaster. Children, like adults, usually experience varying degrees of distress in disaster situations, but most remain functional and are generally resilient (Belfer, 2006; Williams et al., 2008). A review of the empirical literature identified that younger children experienced some short-term behavioural problems, but appeared to be little affected by the disaster itself (Norris et al., 2002). Research on the negative long-term effects on children relate to the death or separation from family, caregivers, friends, teachers and others important to them, including displacement from their communities and peers (Williams et al., 2008). Infants separated from primary caregivers as a result of disaster showed regression and attachment issues (Murray, 2006; Williams et al., 2008). Disrupted social networks and exclusion from them are risk factors for psychological distress, hence the importance of reunification strategies (Meyer, 1982; Bonnerjea, 1994; Brandenburg, 2007; Morris et al., 2007; Doyle, 2010). Children are comforted by re-establishing support systems, including those with peers (Morris et al., 2007; Williams et al., 2008).

The risks for children due to the breakdown of traditional structures and violence are high in countries where long-term conflict or disasters are overlayed onto poverty. Ager et al. (2009) identify tensions in Darfur concerning separated children as the indigenous definition of a separated child differs from that of the international community. Despite conflict and risks to children, protective factors were identified, including complex family and community systems, obligations and social responsibilities and informal care systems that protect separated children. Ager et al. (2009) highlight the importance of focusing on conditions that promote protection with longer-term benefits for reconstruction and development including re-establishing traditional social mechanisms and strengthening community capacity.

\section{Continuity}

The 'continuity principle' (Omar and Alon, 1994) is important to all stages of disaster management and aims at community preservation and restoration. The continuity 
principle informs interventions for children based on re-establishing pre-existing individual, family, organisational and communal routines that mediate disruption caused by disasters, and the importance of child participation in relief efforts (Morris et al., 2007). In the case of ICA post-disaster, heroic and sentimental responses from those outside affected communities directed to 'rescuing' children through adoption immediately postdisaster are at odds with research pointing to the benefits of children healing within their communities. The continuity principle emphasises recognising, mobilising and strengthening local communities in their own recovery.

The Sphere Project (2004) is an initiative launched in 1997 by humanitarian NGOs, the Red Cross and Red Crescent to develop a Humanitarian Charter, minimum standards and an operational framework in disaster assistance. The Sphere initiative began as a response to the Rwandan genocide and is based on the premise that historically humanitarian actions have been insufficient in dealing with the complexities of disasters and their social and cultural implications. Special measures and indicators are identified for children considered part of the larger affected population (Williams, 2006; Williams et al., 2008). These include the maintenance of cultural and religious events including grieving rituals; access for children and adolescents to educational and recreational activities as resources permit; participation by adults and adolescents in relief activities; participation of isolated persons (including orphans) in activities that facilitate inclusion in social networks; the establishment of tracing services for family reunion; mechanisms for taking children's views into consideration in the development of interventions aimed at them; and access to Psychological First Aid for all distressed individuals. Morris et al. (2007) reviewed the relevant literature pertaining to the Sphere standards on social and mental health issues relating to children, and recommendations for post-disaster interventions. They noted a need for more research related to children, a challenge being addressed by the Child and Family Disaster Research Training and Education (DRT) program (Pfefferbaum et al., 2010).

In response to the Haitian disaster, the Interagency Standing Committee (IASC) Mental Health and Psychosocial Support (MHPSS) Reference Group identified keeping families together as a priority and the Mental Health and Psychosocial Support Guidelines in Emergencies Settings (IASC, 2007, 2010) aim at family preservation. The core principles are grounded in human rights, equity, community participation, capacity building and development, and the ethical principle of doing no harm. The IASC identifies a hierarchy of needs beginning with needs for basic services and security, advocacy for careful management of aid bodies, and the provision of credible and accurate information. This is followed by community and family supports for appropriate cultural and religious activities including mourning, participation and consultation, re-establishment of normal routines and activities, maximizing opportunities for people to connect, caring for staff and provision of information about positive coping. Finally, there are focused, non-specialist supports that include Psychological First Aid and specialised mental health services where required. Psychological First Aid is now routinely used in post-disaster situations and requires training, focus on culturally relevant support and practical assistance particularly in relation to reconnecting people (including children) and supporting their strengths, and self-care for workers. It involves a process of contact and engagement, safety and comfort, information gathering, information provision, practical assistance, connecting with social supports and linking with collaborating services (IASC, 2007; Ruzek et al., 2007; Vernberg et al., 2008). 


\section{Implications for adoption}

Children constitute one of the most vulnerable groups in disasters making their protection important. Legal and ethical concerns with the practice of post-disaster child removal for adoption emerge in our review of key events in post-disaster adoption history. While the adjustment of children in adoptive families has been widely researched, the efficacy of ICA in the immediate aftermath of disaster has not been previously examined in light of the psychosocial care literature. Exploring historical adoption practices identifies potential harms to children. These relate to haste, the loosening of safeguards and protective processes in the adoption process and the adoption-centred goals of evacuations. Hasty evacuations force separations from related or unrelated significant others. This is at odds with the findings from the psychosocial care literature which indicate immediate safety, normalisation, stabilisation, re-establishment of routines and social connectedness in the immediate post-disaster period. As a practice, ICA, which represents the legal severance from the birth family, expatriation, the imposition of a new name and new identity on the adoptee, relocation to a new country with different language, food and culture, and a new family, is far removed from the 'continuity principle'. If continuity is considered to benefit the child within his or her community in post-disaster recovery, a large question remains as to who benefits from the radical discontinuities entailed in child removal for adoption?

It is commonly held by advocates for the adoption of children from severely disadvantaged circumstances and disasters that these children have no attachments and no culture as they live in orphanages or on the streets, a view put strongly in an Australian inquiry into intercountry adoption in 2005 (HRSCFHS, 2005). In contrast, the analysis in this article assumes that most children have extended family relationships, relationships with caregivers within orphanages and with peers who represent significant attachments. While not, perhaps, attachments of the kind found in western nuclear families, children in even the most disadvantaged situations are likely to have attachments which stand to be disrupted through their removal. Orphanages do not exist in isolation from the communities in which they exist. There are practices, routines, language and people familiar to the children within them, factors which, though under-researched, are important to acknowledge when considering post-disaster actions. Children's reactions to disaster depend on the degree of destruction and loss they experience (Murray, 2006; Williams et al. 2008). So, a crucial question to be asked is whether child adoption in the immediate post-disaster period ameliorates the child's experience of trauma or loss, or adds to cumulative loss. Arguably, the disruption entailed in evacuation for adoption, and the rupturing of that child's routines and networks may be considered traumatic in itself. To progress ICA immediately postdisaster before the child, significant others (whether family, institutional carers or peers), and community have had the opportunity to normalise their situation, re-establish routines and rebuild capacity is a psychosocial factor to be considered in addition to the other considerations of child rights, reunification strategies and the prevention of trafficking. The inclusion of psychosocial care knowledge in decisions about children adds to existing evidence that questions adoption-driven evacuations post-disaster.

\section{Conclusion}

A consideration of psychosocial care indicates that the immediate post-disaster period is no time for uninformed actions, the commencement of new adoptions or the expedition 
of existing ones. It is a time for caution, assessment and recovery. Adoption-driven rescues showcase the power and influence of adoption groups on the adoption process and bear little relationship to the research evidence on the needs of children. In disaster, adoptiondriven approaches focus on how adoptions may be expedited to meet market demand. Evidence from both the psychosocial care literature and the history of adoption and disaster suggests that post-disaster adoptions may not meet the needs of children and have in many cases caused further harm. In line with the plea from the ISS made to the Special Commission of The Hague Convention in 2010 (ISS,2010), more concerted effort is required by the international community to ensure that market forces do not prevail over considerations of the needs of children in disaster. The market in babies and children feeds off disaster and utilises opportunities to secure access to children for adoption. Vigilance in regulating the activities of organisations and individuals involved in ICA work is essential. An even greater challenge lies in educating and regulating the desires of those in receiving countries who subscribe uncritically to 'rescue by adoption' narratives and minimise the impact that their hunger for children generates in fuelling this market. Sadly, children in disasters continue to be evacuated permanently for adoption without due process, an experience that brings a life-long legacy of loss for many.

\section{References}

Australian Broadcasting Commission (2011) 'Post-war effort needed to rebuild Queensland', http://www. abc.net.au/news/stories/2011/01/13/3112015.htm [accessed 07.02.2011].

Ager, A., Boothby, N. and Bremer, M. (2009 'Using the "protective environment" framework to analyse children's protection needs in Darfur', Disasters, 33, 4, 548-73.

Alam, E. (2010) 'Cyclone disaster vulnerability and response experiences in coastal Bangladesh', Disasters, $34,4,931-54$.

Armistead, A. L. (2010) 'Reflections on the orphan rescue in Haiti: Critical thinking post-disaster', paper presented at the Adoption Summit, Stratford, Ontario, University of Waterloo, 23-26 September.

Armstrong, S and Slaytor, P. (2001) The Colour of Difference: Journeys in Transracial Adoption, Sydney, Australia: The Federation Press.

Balsari, S., Lemery, J., Williams, T. P. and Nelson, B. D. (2010) 'Protecting the children of Haiti', The New England Journal of Medicine, 362, 9, 25.

Bartholet, E. (2010) 'International adoption: the human rights perspective', Global Policy, 1, 1, 91-100.

BBC News (2007) 'Profile: Zoe's Ark', http://news.bbc.co.uk/2/hi/europe/7067374.stm [accessed 05.12.2010].

Becker, S. M. (2009) 'Psychosocial care for women survivors of the tsunami disaster in India', American Journal of Public Health, 99, 4, 654.

Belfer, M. (2006) 'Caring for children and adolescents in the aftermath of natural disasters', International Review of Psychiatry, 18, 6, 523-8.

Bergquist, K. J. S. (2009) 'Operation Babylift or Babyabduction?: implications of the Hague Convention on the humanitarian evacuation and "rescue" of children', International Social Work, 52, 5, 621-33.

Bland, S. (1997) 'Social network disturbances and psychological distress following earthquake evacuation', Journal of Nervous and Mental Disease, 185, 3, 188-95.

Bonnerjea, L. (1994) 'Disasters, family tracing and children's rights: some questions about the best interests of separated children', Disasters, 18, 3, 277-83, doi: 10.1111/j.1467-7717.

Boyden, J. O. (1994) 'Children's experience of conflict related emergencies: some implications for relief policy and practice', Disasters, 18, 3, 254-67.

Brandenburg, M. A., Watkins, S. M., Brandenburg, K. L. and Schieche, C. (2007) 'Operation Child-ID: reunifying children with their legal guardians after Hurricane Katrina', Disaster, 31, 3, $277-87$. 
Brookfield, T. (2009) 'Maverick mothers and mercy flights: Canada's controversial introduction to international adoption', Journal of the Canadian Historical Association, 19, 1, 307-30.

Brown, B. M. (1980) 'Operation Babylift and the exigencies of war: who should have custody of orphans', Northern Kentucky Law Review, 6, 3, 81-92.

Cameron, P. A., Mitra, B., Fitzgerald, M., Scheinkestel, C. D., Stripp, A., Batey, C., et al. (2009) 'Black Saturday: the immediate impact of the February 2009 bushfires in Victoria, Australia', The Medical Journal of Australia, 191, 1, 11-16.

Cherot, N. (2009) 'Storytelling and ethnographic intersections: Vietnamese adoptees and rescue narratives', Qualitative Inquiry, 15, 1, 113-48.

Crosby, S. S. and Grodin, M. A. (2007) 'Ethical considerations in crisis and humanitarian interventions: the view from home', Ethics and Behavior, 17, 2, 203-5.

Cuthbert, D., Spark, C. and Murphy, K. (2009) "That was then, but this is now": historical perspectives on intercountry and domestic child adoption in Australian public policy', Journal of Historical Sociology, 23, 3, 427-52.

Dambach, M. and Baglietto, C. (2010) 'Haiti: "Expediting" intercountry adoptions in the aftermath of a natural disaster ... preventing future harm, International Social Services', http://www.iss-ssi. org/2009/assets/files/Haiti\%20ISS\%20final-\%20foreword.pdf [accessed 27.11.2010].

Doyle, J. (2010) Misguided Kindness: Making the Right Decisions for Children in Emergencies, London: Save the Children Fund, http://www.crin.org/docs/Misguided_Kindness.pdf [accessed 06.01.2011].

Edwards, P. (1997) A Nation at War: Australian Politics, Society and Diplomacy during the Vietnam War 1965-1975, St Leonards, NSW: Allen \&Unwin.

Enarson, E. and Phillips, B. (2008) 'Invitation to a new feminist disaster sociology: integrating feminist theory and methods', in B. Phillips and B. H. Morrow (eds.), Women and Disasters: From Theory to Practice, USA: International Research Committee on Disasters, pp. 41-74.

Foster, D., Davies, S. and Steele, H. (2003) 'The evacuation of British children during World War II: a preliminary investigation into the long-term psychological effects', Aging and Mental Health, 7, 5, 398-408.

Fronek, P. (2009) 'Intercountry adoption in Australia: a natural evolution or purposeful actions', in C. Spark and D. Cuthbert (eds.), Other People's Children: Adoption in Australia, Melbourne: Australian Scholarly Press, pp. 37-54.

Fronek, P. (2012) 'Operation Babylift: advancing intercountry adoption into Australia', Journal of Australian Studies, in press.

Fronek, P. and Cuthbert, D. (2012) 'The future of intercountry adoption: a paradigm shift for this century', International Journal of Social Welfare, 21, 2, 215-24.

Fronek, P. and Tilse, C. (2010) 'Controversy and its implications for the practice of contemporary social work in intercountry adoptions: a Korean-Australian case study', Australian Social Work, 63, 4, 445-59.

Hearst, A. (2010) 'Between Restavek and relocation: children and communities in transnational adoption', The Journal of the History of Childhood and Youth, 3, 2, 267-92.

Hobfoll, S. E., Watson, P. J., Bell, C. C., Bryant, R. A., Brymer, M. J., Friedman, M. J., et al. (2007) 'Five essential elements of immediate and mid-term mass trauma interventions: empirical evidence', Psychiatry, 70, 4, 283.

House of Representatives Standing Committee on Family and Human Services (HRSCFHS) (2005) Overseas Adoption in Australia: The Report on the Inquiry into Adoption of Children from Overseas, Canberra: House of Representatives Standing Committee on Family and Human Services.

IASC (2007) IASC Guidelines on Mental Health and Psychosocial Support in Emergency Settings, Geneva: Inter-Agency Standing committee, WHO.

IASC (2010) Guidance Note for Mental health and Psychosocial Support Haiti Earthquake Emergency Response - January 2010, Inter-Agency Standing Committee Reference Group on Mental Health and Psychosocial Support, World Health Organisation.

\section{CAMBRIDGE JDURNALS}


ICRC (2004) Inter-Agency Guiding Principles on Unaccompanied and Separated Children, Geneva: International Committee of the Red Cross.

International Social Services (ISS) (2010) 'The grey zones of intercountry adoption', Hague Conference on Private International Law, The Hague, The Netherlands.

Kelley, M. (2010) 'Commentary: should international adoption be part of humanitarian aid efforts? Lessons from Haiti', Bioethics, 24, 7, 373-80.

Lauten, A. W. and Lietz, K. (2008) 'A look at the standards gap: comparing child protection responses in the aftermath of Hurricane Katrina and the Indian Ocean Tsunami', Children, Youth and Environments, $18,1,158-201$.

Leivesley, S. (1980) 'The social consequences of Australian disasters', Disasters, 4, 1, 30-7.

Lesnick, B. and Urek, M. (2010) 'Traps of humanitarian aid: observations from a village community in Sri Lanka', European Journal of Social Work, doi: 10.1080/13691451003690908.

Margesson, R. and Taft-Morales, M. (2010) Haiti Earthquake: Crisis and Response, USA: Congressional Research Service, Library of Congress.

Mark, C. (2008) 'Disaster mythology: looting in New Orleans', Disaster Prevention and Management, 17, 4, 519.

Meyer, M. (1982) 'Tracing: an aspect of disaster assistance', Disasters, 8, 2, 149-53.

Morris, J., Van Ommeren, M., Belfer, M., Saxena, S. and Saraceno, B. (2007) 'Children and the Sphere standard on mental and social aspects of health', Disaster, 31, 1, 71-90.

Murray, J. (2006) 'Addressing the psychosocial needs of children following disaster', Journal of Specialist Pediatric Nursing, 11, 2, 133-7.

Nicolas, G., Schwartz, B. and Pierre, E. (2009) 'Weathering the storms like bamboo: the strengths of Haitians in coping with natural disasters', in A. Kalayjian, D. Eugene and G. Reyes (eds.), International Handbook of Emotional Healing: Ritual and Practices for Resilience After Mass Trauma, Westport, CT: Greenwood Publishing, pp. 93-106.

Norris, F. H., Friedman, M. J., Watson, P. J., Byrne, C. M., Diaz, E. and Kaniasty, K. (2002) '60,000 disaster victims speak: Part I - an empirical review of the empirical literature, 1981-2001', Psychiatry, 65, $3,207$.

Omar, H. and Alanon, N. (1994) 'The continuity principle: a unified approach to disaster and trauma', American Journal of Community Psychology and Psychiatry Journal, 22, 2, 27386.

Pack-Patton, D. K. (2010) International Disaster Psychology: Moving toward a Standardized Model, Newberg, OR: George Fox University.

Payne-Price, A. C.,(1981) 'Ethnic variations on fosterage and adoption', Anthropological Quarterly, 54, 3, 134-45.

Pfefferbaum, B., Houston, J. B., Reyes, G., Steinberg, A. M., Pynoos, R. S., Fairbank, J. A., et al. (2010) 'Building national capacity for child and family disaster mental health research', Professional Psychology: Research and Practice, 41, 1, 26-33.

Poe, A. (2010,) 'UNICEF's effective attack on intercountry adoption', Washington Post, 30 November, http:// communities.washingtontimes.com/neighborhood/red-thread-adoptive-family-forum/2010/nov/30/ unicefs-effective-attack-inter-country-adoption/ [accessed 14.03.2011].

Raphael, B. (2005) 'Crowds and other collectives: complexities of human behaviors in mass emergencies', Psychiatry, 68, 2, 115-20.

Rofi, A., Doocy, S. and Robinson, C. (2006) 'Tsunami mortality and displacement in Aceh province, Indonesia', Disasters, 30, 3, 340-50.

Rotabi, K. S. and Bergquist, K. J. S. (2010) 'Vulnerable children in the aftermath of Haiti's earthquake of 2010: a call for sound policy and processes to prevent international child sales and theft', Journal of Global Social Work Practice, 3, 1, http://www.globalsocialwork.org/vol3no1/Rotabi.html [accessed 14.03.2011].

Ruzek, J. I., Brymer, M. J., Jacobs, A. K., Layne, C. M., Vernberg, E. M. and Watson, P. J. (2007) 'Psychological First Aid', Journal of Mental Health Counseling, 29, 1, 17-49.

\section{CAMBRIDGE JDURNALS}


Sarri, R., Baik, Y. and Bombyk, M. (1998) 'Goal displacement and dependency in South-Korean - United States intercountry adoption', Children and Youth Services Review, 20, 1/2, 87-114.

Selman, P. (2009) 'The rise and fall of intercountry adoption in the 21 st century', International Social Work, $52,5,575-94$.

Sommers-Flanagan, R. (2007) 'Ethical considerations in crisis and humanitarian interventions', Ethics and Behavior, 17, 2, 187-202.

Sphere Project (2004) Humanitarian Charter and Minimum Standards in Disaster Response, Geneva Switzerland: Steering Committee for Humanitarian Response (SCHR).

Thirumurthy, V., Uma, V. and Muturam, R. N. (2008) 'Tsunami: hope in the midst of disaster', Childhood Education, 85, 1, 39-46.

Thompson, G. (2010) 'After Haiti quake, the chaos of US adoptions', New York Times, http://www. nytimes.com/2010/08/04/world/americas/04adoption.html [accessed 23.11.2010].

Tribe, R. (2007) 'Health pluralism: a more appropriate alternative to western models of therapy in the context of civil conflict and natural disaster in Sri Lanka', Journal of Refugee Studies, 20, 1, 21-36.

Machel, G. (1996) Promotion and Protection of the Rights of Children: Impact of Armed Conflict on Children (Machel Report), United Nations Department for Policy Coordination and Sustainable Development (DPCSD), http://www.unicef.org/ graca/a51-306_en.pdf [accessed 01.01.2011].

UN/ISDR (2007) Disaster Statistics, http://www.unisdr.org/disaster-statistics/ occurrencetrends-centurv.htm [accessed 06.12.2010].

UNICEF (2009) 'Orphans', press release, http://www.unicef.org/media/media_45279.html [accessed 05.12.2010].

UNICEF (2010) 'UNICEF's position on inter-country adoption', press release, http://www.unicef. org/media/media_41918.html [accessed 05.12.2010].

Vernberg, E. M., Steinberg, A. M., Jacobs, A. K., Brymer, M. J., Watson, P. J., Osofsky, J. D., et al. (2008) 'Innovations in disaster mental health: Psychological First Aid', Professional Psychology: Research and Practice, 39, 4, 381-8.

Williams, R. (2006) 'The psychosocial consequences for children and young people who are exposed to terrorism, war, conflict and natural disasters', Current Opinion in Psychiatry, 19, 4, 337-49.

Williams, R., Alexander, D., Bolsover, D. and Bakke, F. K. (2008) 'Children, resilience and disasters: recent evidence that should influence a model of psychosocial care', Current Opinion in Psychiatry, 21, 4, $338-44$.

Zigler, E. (1975) 'The Vietnamese children's airlift: too little and too late', http://eric.ed.gov/ERICWebPortal/ custom/portlets/recordDetails/detailmini.jsp?_nfpb=trueand_andERICExtSearch_SearchValue_0= ED119827andERICExtSearch_SearchType_0=noandaccno=ED119827 [accessed 13.03.2010].

Zigler, E. (1976) 'A developmental psychologist's view of Operation Babylift', American Psychologist, 31, 5, 329-40. 